Article

\title{
Analysis of Urban Drivable and Walkable Street Networks of the ASEAN Smart Cities Network
}

\author{
Pengjun Zhao ${ }^{1} \mathbb{D}$, Yat Yen ${ }^{1,2, *}$, Earl Bailey ${ }^{3}$ and Muhammad Tayyab Sohail ${ }^{4}$ (D) \\ 1 College of Urban and Environmental Sciences, Peking University, Beijing 100871, China; \\ pengjun.zhao@pku.edu.cn \\ 2 Center for Khmer Studies, Phnom Penh 12304, Cambodia \\ 3 Faculty of the Built Environment (FOBE), University of Technology, Jamaica, Kingston 12402, Jamaica; \\ earl.bailey@utech.edu.jm \\ 4 School of Management, Xi'an Jiaotong University, Xi'an 710049, China; tayyabsohail@xitu.edu.cn \\ * Correspondence: yenyat_cambodia@pku.edu.cn; Tel.: +86-156-6542-2787
}

Received: 2 August 2019; Accepted: 10 October 2019; Published: 16 October 2019

\begin{abstract}
Making transport systems sustainable is a topic that has attracted the attention of many researchers and urban planners. The Association of Southeast Asian Nations (ASEAN) Smart Cities Network (ASCN) was initiated to develop a sustainable transport system in the ASEAN countries. A comprehensive understanding of street networks (SNs) can contribute significantly to the achievement of this initiative. Therefore, this paper measured and compared characteristics of drivable street networks (DSNs) and walkable street networks (WSNs) of the 26 ASCN pilot cities by applying multiple network metrics. The OSMnx tool was used to download and analyse WSNs and DSNs from the OpenStreetMap. The findings present the topological and geometric characteristics of WSNs and DSNs that are diverse and characterized by different factors. The cities with orthogonal street grids, high street density, intersection density, and fewer cul-de-sacs have good accessibility to reach destinations. In contrast, some other cities have more curvilinear and circuitous SNs with many missing links to other streets, which in turn are prone to traffic disruption. The study highlights the important features of SNs that have significant implications for future designs of SNs in the ASCN whose goal is to make cities smart and liveable for ASEAN members.
\end{abstract}

Keywords: OSMnx; OpenStreetMap; street network analysis; urban morphology; smart city

\section{Introduction}

The population density of the cities in the ten member states of the Association of South-East Asian Nations (ASEAN) is expanding in an unprecedented way and surpassing other regions of Asia. The combined population of ASEAN countries is more than 630 million people, and by 2030, another 90 million people are expected to live in the ASEAN cities. ASEAN states represent the sixth-largest economy in the world with a combined GDP per capita of US\$4034 in 2016 [1,2]. The small and midsized cities with a population between 200,000 to 2 million people will help drive $40 \%$ of the region's growth in the future [3]. Inevitably, this rapid growth will lead to many challenges, particularly in the large cities of the region. One of the main challenges is traffic congestion and accidents that are estimated to cost $2-5 \%$ of GDP annually for every city in the region [2]. The role played by transportation systems in providing efficient mobility and accessibility to keep the urban economy growing is particularly significant. To date, some smart solutions concentrating on important urban sectors are available, including smart transportation infrastructure and other lifeline services. Applying new technologies and innovations could be a good means to solve urban issues and to use intensive resources in a more efficient way in this region [4]. The unique characteristics of ASEAN cities influence the performance 
of specific applications of smart technologies. Like other cities in the world, every city in this region has a different form of government, socio-economic system, and level of technological maturity, as well as substantially different living standards among the people. In terms of transport systems, Singapore is a leading city whose people have access to different modes of travel with advanced technologies. For example, the rapid transit system (RTS) consists of four mass rail transit (MRT) systems and a light rail transit (LRT) system that make about 1.7 million passenger trips daily. Bus rapid transit (BRT) running on 344 routes serves an average daily ridership of more than 3 million [5]. However, neither MRT nor LRT exist in Cambodian cities or some other cities in the region. Phnom Penh, the capital of Cambodia, has only about 240 public buses running on 13 bus routes to accommodate a daily ridership about 20,000. Therefore, the levels of success in smart transport infrastructure vary significantly from city to city, and the success of Singapore in applying smart technologies in the transport system could be a good lesson for other cities. Woetzel et al. [4] predict that if smart technologies are applied for urban development, ASEAN countries could remove about 270,000 kilotons of greenhouse gas (GHG) emissions and save approximately 5000 lives from traffic crashes and other risks. The installation of intelligent traffic and transit systems could save up to 8 million man-years in annual commuting time. Moreover, the Mckinsey Global Institute (MGC) estimated that smart technologies could help ASEAN countries create about 1.5 million jobs and save living costs of about $\$ 16$ billion yearly [4].

Considering the potential benefits of smart technologies for urban development, a smart city initiative was launched in Singapore in 2018 to support the Master Plan on ASEAN Connectivity 2025. At this first stage, a total of 26 pilot cities were selected from the member states to form the ASEAN Smart Cities Network (ASCN) as a collaborative platform for smart and sustainable urban development. The smart technologies and innovation are to be the main enablers for this initiative. The ASCN framework prioritizes three strategic outputs: high living standards, competitive economies, and sustainable natural environments. Fundamentally, the ASCN focuses on civic and social engagement, health and well-being, safety and security, quality natural environment, built infrastructure, and industry and innovation [3].

To achieve the goals of the above-described initiative, it is essential to understand the challenges of each pilot city and then set up a clear strategic policy to overcome them. Street networks (SNs) are one of the main elements of the transport systems that require an in-depth study. Sufficient information on SNs helps planners and policymakers retrofit the old streets as well as design better new SNs that are resilient, connected, safe, and accessible to different modes of travel. This study shows how information about SNs can help urban planners in this region to understand the differences between drivable street networks (DSNs) and walkable street networks (WSNs) of the individual pilot cities. Not only were the characteristics of DSNs and WSNs analysed, but their topological and geometrical features were also measured by multiple network metrics. The findings provide clear pictures of the SNs in the 26 cities, thus enabling urban planners and policymakers to set policy and development scenarios for sustainable transport systems. The datasets of the SN types for the pilot cities were also produced and stored for future use.

This paper is organized as follows. First, it introduces the background of the ASCN and the purpose of the study. Then it reviews the shortcomings and current challenges of urban and transport development in ASCN cities. Next, it introduces the methodology and data processing techniques implemented to produce the empirical findings. In the following section, the study presents the results with illustrative tables and figures for the SNs of the 26 pilot cities. The study concludes with a discussion and offers suggestions on how the results of the study could be used and implemented.

\section{Literature Review}

\subsection{Street Networks of the ASCN}

SNs play a vital role in people's daily lives and contribute significantly to socio-economic activities. Many countries in Europe and North America have concentrated on the analysis of SNs in terms of 
sustainable transportation and research planning [6,7]. However, the literature on $\mathrm{SNs}$ in the member states of the ASEAN countries remains scarce [5,7]. Some studies in the context of ASEAN have only focused on general SNs of an individual city [8]. Researchers have also noted that most of the studies in developing countries measure only SNs by car [9], bike [10], transit [11], and train [12], but comparative analyses of DSNs versus WSNs have not been done [13]. Most of the studies that are available across this region focus mainly on land use [14], energy [15], general SNs [16], transport systems [17], and traffic issues [18]. Specifically, the literature providing a comparative analysis of DSNs and WSNs in the member cities of the ASCN is scant. Therefore, access to geospatial datasets for SNs and other urban data is a considerable challenge, which requires excessive data processing and simplifications $[19,20]$. Our study has yielded reproducible street datasets for each ASCN pilot city.

The ASCN cities have diverse geographies, as well as various historical, social, cultural, and economic backgrounds [21]. The different patterns of their SNs fundamentally depend on the scope of city planning and decision-making, geographical location, climate, economic growth, and technological adoption. Some cities have irregular (organic) street patterns with zigzag streets while others have a hierarchical (gridiron) structure with regular, rectilinear, curvilinear, orthogonal, and tree-like patterns [22]. Topographically, the majority of the cities in the ASCN, such as Bangkok [23], Manila City [24], and Ho Chi Minh City [25], are located on flatlands close to rivers or sea coasts which are vulnerable to monsoon flooding and storms [26]. Road infrastructure is commonly destroyed by these natural disasters. With an understanding of the street patterns, planners can design streets that are highly adaptive and resistant to natural disasters and other geo-hazards [25].

\subsection{Transport Development in the ASCN}

The levels of transport development in the pilot cities of the ASCN depend primarily on the socio-economic prosperity of the individual country and city. Countries with good socio-economic conditions are able to provide better opportunities for transportation infrastructure [27]. For example, Cambodia is the least developed country in the region and roads are the primary means of transport, accounting for $69 \%$ of total freight and $65 \%$ of passenger traffic. However, Cambodia's roads are mostly underdeveloped, and only the first-class national highways are asphaltic roads. Of the present total SNs, only about $50 \%$ is hard-surfaced and in good condition. About $50 \%$ of the SNs were built of crushed stone, gravel, or compacted earth. The quality of the existing road infrastructure is relatively low compared to other countries in the region [28]. The World Bank has also indicated that Cambodians have limited access to the necessary infrastructure and live far from jobs and services [29]. In contrast, Singapore has one of the most cost-efficient public transportation networks in the ASEAN region and the multiple travel modes in this country are accessible to the public, including three lines of subway networks [30].

Contemporary factors driving transport development are linked to rapid rates of urbanization and population growth. Some cities such as Jakarta, Ho Chi Minh City, and Bangkok have a population of over 5 million, while other midsized cities, such as Da Nang, Vientiane, and Makassar have populations of less than 2 million. Economically, Singapore occupies a top tier, Kuala Lumpur is the second tier, Bangkok and Manila City are the third tier, and Jakarta and Ho Chi Minh City are the fourth tier in the region [31,32]. Woetzel et al. [4] classify the ASEAN cities $(\geq 230)$ into four categories named "sandboxes", "prime movers", "emerging champions", and "agile seedbeds". Only Singapore fits the first classification of a smart city sandbox that applies a comprehensive technological infrastructure in every sector of urban life. The second category of prime movers are the large cities that serve millions of people, including Bangkok, Ho Chi Minh City, Jakarta, Kuala Lumpur, and Manila City. In the third category, the emerging champions are midsized cities with populations of around 2 million, such as Phnom Penh, Hanoi, Cebu, Yangon, and Davao. These cities need more investment to boost their growth and development. Lastly, agile seedbeds are the cities with $\leq 1$ million people.

People living in small and the least developed cities have limited access to public transport. Thus, private operators play a significant role in providing transport services. Paratransit (i.e., motorcycle 
taxis, rickshaws, and mini-buses) contributes substantially to the transport service in the ASCN cities as it is convenient and flexible, and also has a low fare [33]. Moreover, paratransit services contribute significantly to the socio-economic growth and job opportunities for poor and low-skilled people. However, due to the rapid growth of service providers and low levels of knowledge among paratransit drivers about traffic rules, people frequently criticise these drivers for bad driving behaviours, traffic congestion, accidents, and emissions.

Inadequate transport infrastructure provision for different modes of travel leads to increasing numbers of private vehicles, which in turn results in road congestion, accidents, economic retardation, with a corresponding deterioration in the quality of life [16]. When automobiles dominate the urban spaces and people's lives, active modes of travel, such as walking and cycling, become less attractive [34]. For instance, in Indonesia, private vehicle ownership occupies $79 \%$ of all travel modes [35]. In Ho Chi Minh City, around 90\% of road transport substantially relies on motorbikes and private cars, whereas walking and cycling represent less than 5\% [36]. Switching from private automobile use to public transport or walking and cycling is difficult if public transport and pedestrian sidewalks are not widely accessible. In order to promote sustainable urban mobility for all people, improving the safety and accessibility of SNs for pedestrians and cyclists is necessary [37]. However, where to make improvements and what should be improved on the SNs are the questions that urban planners and researchers need to answer. For example, can smart technologies be applied to the transport systems in every city of the ASCN? An in-depth study on the SNs of the ASCN has the potential to answer some of these questions. A morphological analysis of the DSNs and WSNs of the ASCN should be primarily prioritized as a means to obtain insightful information about the $\mathrm{SNs}$ and urban patterns for the pilot cities. Therefore, the objective of this study is to answer the above-mentioned questions and thus contribute to the understanding of the SNs in the major cities in the ASCN.

\section{Materials and Methods}

\subsection{Area Selection}

The study examined 26 selected pilot cities in the ASCN (Figure 1). Based on the idea of [27], the cities were divided into three sub-groups according to their population (Table 1). The 8 cities with a population $\leq 800,000$ were regarded as "small cities", the 12 cities with a population between 800,000 and 3 million were defined as "midsized cities" (cities), and the 6 cities with a population $\geq 3$ million were referred to as "metropolises". The area size, population, and population density were provided by chief officers of each pilot city and stored on the website of the Ministry of Foreign Affairs of Singapore (https://www.mfa.gov.sg/SINGAPORES-FOREIGN-POLICY/ASEAN2018/ASEAN-Infographic-and-ASEAN-Smart-Cities-Network---ASCN, accessed in January 2019). 


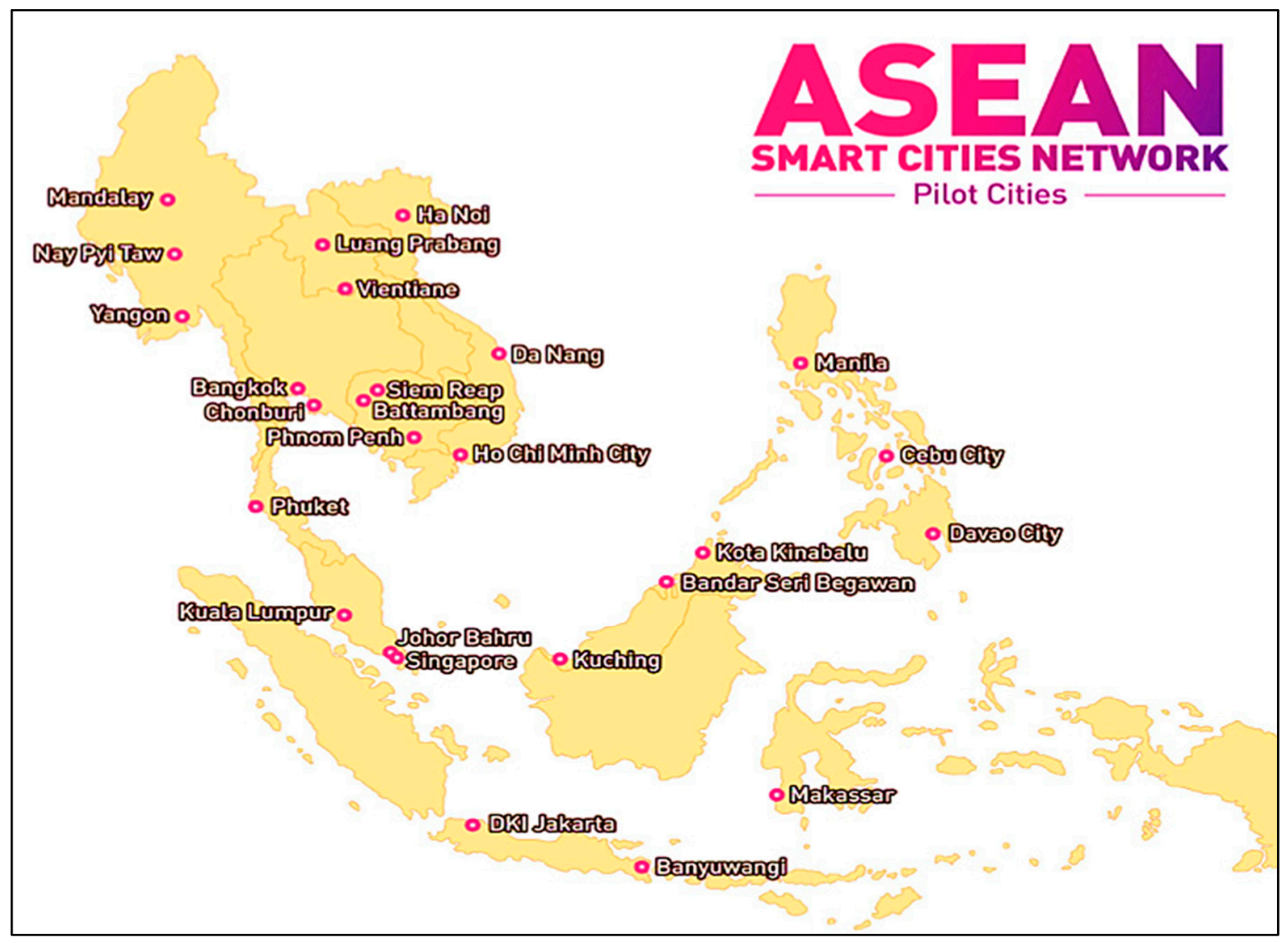

Figure 1. Map of the 26 pilot cities in the Association of Southeast Asian Nations (ASEAN) smart cities network (ASCN) showing their locations in the ASEAN member states.

Table 1. Area, population, and density of the 26 pilot cities of ASCN from the least to most populous cities.

\begin{tabular}{|c|c|c|c|c|c|c|c|}
\hline Cities & $\begin{array}{c}\text { Area } \\
\left(\mathrm{km}^{2}\right)\end{array}$ & $\begin{array}{l}\text { Population } \\
\text { (million) }\end{array}$ & Density/km² & Cities & $\begin{array}{c}\text { Area } \\
\left(\mathrm{km}^{2}\right)\end{array}$ & $\begin{array}{l}\text { Population } \\
\text { (million) }\end{array}$ & Density $/ \mathrm{km}^{2}$ \\
\hline $\begin{array}{c}\text { Bandar Seri } \\
\text { Begawan, BN }\end{array}$ & 100 & 0.06 & 641 & $\begin{array}{c}\text { Johor Bahru, } \\
\text { MA }\end{array}$ & 220 & 1.5 & 6909 \\
\hline $\begin{array}{c}\text { Battambang, } \\
\mathrm{KH}\end{array}$ & 115 & 0.16 & 1395 & $\begin{array}{l}\text { Banyu Wangi, } \\
\text { IND }\end{array}$ & 5783 & 1.60 & 277 \\
\hline Chonburi, TH & 43 & 0.22 & 5000 & Davao, $\mathrm{PH}$ & 2444 & 1.63 & 699 \\
\hline $\begin{array}{l}\text { Siem Reap, } \\
\mathrm{KH}\end{array}$ & 425 & 0.27 & 632 & Makassar, IND & 199 & 1.77 & 7400 \\
\hline Phutket, TH & 543 & 0.40 & 719 & Manila City, PH & 39 & 1.78 & 46 \\
\hline $\begin{array}{c}\text { Luang } \\
\text { Prabang, Lao }\end{array}$ & 16,875 & 0.43 & 26 & $\begin{array}{c}\text { Kuala Lumpur, } \\
\text { MA }\end{array}$ & 243 & 1.80 & 7377 \\
\hline $\begin{array}{c}\text { Kota Kinabalu, } \\
\text { BN }\end{array}$ & 366 & 0.45 & 1290 & $\begin{array}{l}\text { Phnom Penh, } \\
\text { KH }\end{array}$ & 693 & 2.80 & 4040 \\
\hline Kuching, MA & 2031 & 0.68 & 336 & Yangon, MY & 576 & 5.21 & 9045 \\
\hline Vientiane, Lao & 130 & 0.70 & 209 & Singapore & 720 & 5.61 & 7796 \\
\hline Cebu, PH & 315 & 0.87 & 2761 & Hanoi, VN & 3359 & 7.60 & 2182 \\
\hline $\begin{array}{l}\text { Naypyidaw, } \\
\text { MY }\end{array}$ & 7054 & 0.93 & 131 & $\begin{array}{l}\text { Ho Chi Minh } \\
\text { City, VN }\end{array}$ & 2096 & 8.20 & 4025 \\
\hline Da Nang, VN & 1285 & 1.00 & 814 & Bangkok, TH & 1569 & 8.28 & 5300 \\
\hline Mandalay, MY & 285 & 1.23 & 4300 & Jakarta, IND & 662 & 10.10 & 15,367 \\
\hline
\end{tabular}

Note: $\mathrm{BN}=$ Brunei, $\mathrm{KH}=$ Cambodia, $\mathrm{TH}=$ Thailand, VN = Vietnam, MY = Myanmar, MA = Malaysia, $\mathrm{PH}=$ Philippines, $\mathrm{SG}=$ Singapore, IND = Indonesia, and Lao. 


\subsection{Street Network Measures}

Critical network metrics were applied to measure DSNs and WSNs. Brief definitions and illustrations of the measures are summarized in Table 2 and Figure 2. A thorough description of these metrics can be consulted in, for example, $[20,38,39]$.

Table 2. Definitions of network metrics.

\begin{tabular}{|c|c|}
\hline Network Metrics & Definitions \\
\hline Node & A point of intersection within a specific network. \\
\hline Edge & An interface between streets and the adjoining buildings and plots. \\
\hline Betweenness centrality & A prediction of how each street network (SN) links to possible shortest paths to pass through the node [38]. \\
\hline Closeness centrality & A sum of the distance from a node (origin) to all reachable nodes (destinations) in SNs [40]. \\
\hline Average street length & A linear proxy for block size that specifies the network's grain [13]. \\
\hline Total street length & Sum of edge lengths in the undirected representation of the network. \\
\hline Total edge length & Sum of edge lengths in the network. \\
\hline Node density & The number of nodes in a network divided by area in $\mathrm{km}^{2}$. \\
\hline Edge density & Total edge length divided by area in $\mathrm{km}^{2}$. \\
\hline Street density & A measurement of the total street length divided by the areas in $\mathrm{km}^{2}$. \\
\hline $\begin{array}{l}\text { Average streets per } \\
\text { node }\end{array}$ & $\begin{array}{l}\text { The average number of physical streets that emanate from each node (i.e., intersections or cul-de-sacs). Its } \\
\text { distribution and proportion characterize the type, pervasiveness, and spatial dispersal of network } \\
\text { connectedness and cul-de-sacs. }\end{array}$ \\
\hline Average circuity & $\begin{array}{l}\text { A ratio of shortest network distances to straight-line distances between origin and destination. The average of } \\
\text { circuity is at about } 1.2 \text { times the Euclidean distance for stylized road networks [9]. }\end{array}$ \\
\hline
\end{tabular}

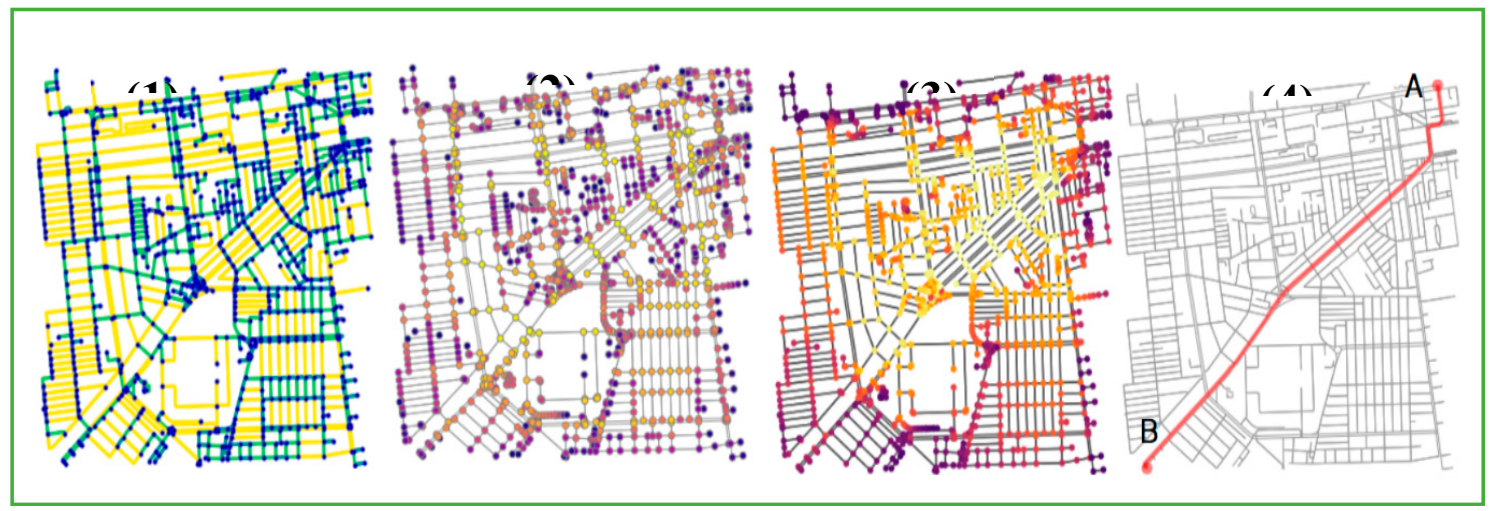

Figure 2. The network metrics of Phnom Penh city. (1) Node (dark blue) and edge (yellow), (2) betweenness centrality from lowest (dark) to highest (light), (3) closeness centrality from the lowest (dark) and highest (light), and (4) route distance from A to B.

\subsection{Data Processing}

The study used the OSMnx toolbox to extract the DSNs and WSNs of each city from OSM data in December 2018 by using codes developed by Boeing [38]. The simple codes allow users of the OSMnx to extract and analyse different types of SNs consistently. The Jupyter notebook and OSMnx package were installed in Anaconda v.4.5.11, and then we ran the codes in Python v.3.7 to download the SNs. The topology and geometry of the SNs could be automatically simplified and corrected by the OSMnx so that nodes could accurately represent intersections and cul-de-sacs (Figure 3). Users can download an area of interest by a place name or an address in their area and then save SNs as shapefiles.

This study firstly used OSMnx to buffer each geometry by $1500 \mathrm{~m}$ from each city's centre point and then download the network metrics from the OSM within that buffer. The small areas may not represent all the city's areas but are useful for comparisons across cities at a small spatial scale [41]. The SNs are dense in the city centre for the majority of the cities. Thus, within this small area from the central point, we are able to ensure that the SNs and results are consistently comparable from one city to another. Next, the graphs' topography and metrics of the SNs were produced, corrected, and calculated for each network type. Lastly, each SN was saved as a shapefile. 


\subsection{Data Validation}

Because the SN datasets were extracted from the OSM data, the reliability and accuracy of the data are questionable. A large body of literature has assessed the quality and accuracy of the OSM data by using different tools and methods. For example, Mülligann et al. (2011) analysed the accuracy of point of interest (POI) of the OSM datasets [42]. In addition, Mülligann, Zhang, and Pfoser [43] assessed the fitness-for-use of the OSM POI for urban change. In parallel, Touya et al. [44] applied multiple models to measure the quality of the OSM datasets. In general, researchers used two approaches to assess the quality of the OSM data. For the first approach, the researchers compare the OSM data with reference data to measure the data completeness and accuracy. For example, Ather [45] compared the quality of the OSM data of 4 regions in London within $25 \mathrm{~km}^{2}$ with the Ordnance Survey's MasterMap. The result indicates that the lowest position accuracy of the OSM dataset was $80.80 \%$. For the second approach, the researchers evaluate the trustworthiness of the methods/tools that have been applied to edit or change the OSM data. Although the OSM is a volunteered geographical data that allows users to edit and change its features, the edits and changes are generally made for the sake of quality improvement of features and for minimizing the heterogeneity of the thematic attributes.

Similar to a study by Basiri et al. [46], our research relies on two approaches in order to ensure the accuracy and reliability of the data. First, the latitude and longitude point of each study area was checked in the Nomitim Search (https://nominatim.openstreetmap.org/) and Google Map (https://www.google.com/maps/) to make sure that the address point was selected from the main hub (city centre). The extracted street datasets were compared with a reference map (OpenStreetMap and Google Map) in ArcGIS 10.5 to ensure that the SN data fell within the study area. Another approach was to use predefined automated rules which can detect and correct bugs and errors. Boeing [38] confirmed that the OSMnx is capable of building topologically corrected SNs automatically, which in turn allows nodes to represent intersections and cul-de-sacs. For example, Figure 3 illustrates the simplification and correction of nodes so as to make sure that the remaining nodes represent the intersections and cul-de-sacs precisely. After simplifications and corrections, SNs were then calculated to measure other network metrics.

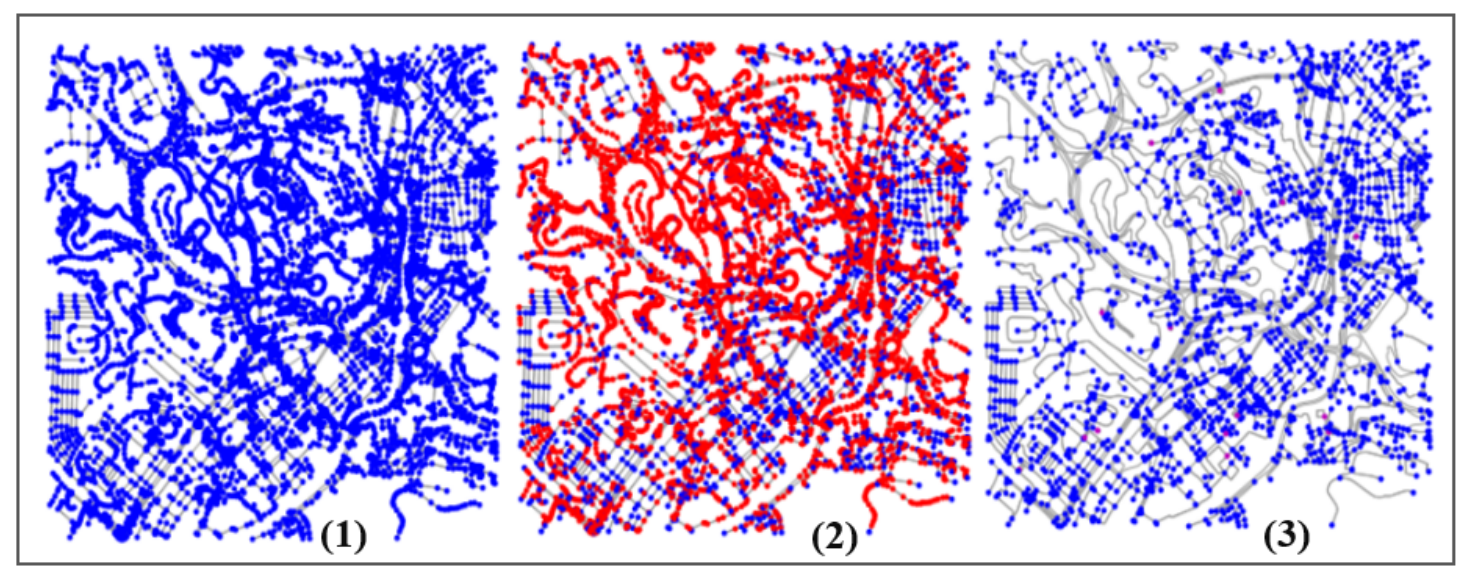

Figure 3. The simplification and correction of nodes of Kuala Lumpur within a $1.5 \mathrm{~km}$ buffer: (1) the extracted SNs, (2) number of red nodes to be removed, and (3) number of nodes and cul-de-sacs after correction.

\subsection{Data Analysis}

To compare the differences between DSNs and WSNs, the $\varphi$ ratio of the average driving circuity to the average walking circuity of the 26 cities was calculated:

$$
\varphi=\frac{\left(\mu_{d}-1\right)}{\left(\mu_{w}-1\right)}
$$


where $\mu_{w}$ is the mean circuity of the trips along its WSNs and $\mu_{d}$ is the mean circuity of the trips along its DSNs. The $\varphi$ ratio was substituted by 1 for each term since the minimum circuity is 1 [9]. The differences in the $\varphi$ ratio show how much distance can be saved between walking and driving when a more directed route is taken. Furthermore, to measure which cities out of the 26 analysed are more walkable or drivable, the effect size as Cohen's d of each city was calculated as follows:

$$
d_{d / w}=\frac{\left(\mu_{d}-\mu_{w}\right)}{\sqrt{\frac{\left(n_{d}-1\right) \delta_{d}^{2}+\left(n_{w}-1\right) \delta_{w}^{2}}{\left(n_{d}-1\right)+\left(n_{w}-1\right)}}}
$$

where $d_{d / w}$ is the effect size of the difference between $\mu_{w}$ and $\mu_{d}$, while $n_{w}, n_{d}$, and $\delta_{w}^{2}, \delta_{d}^{2}$ are sample sizes and variances for driving and walking routes, respectively. Cohen's d substitutes the mean difference in route circuity by the pooled standard deviation. If $\mu_{d}$ is greater than $\mu_{w}$, it means that the walking route allows for more direct routes. Conversely, if $\mu_{w}$ is greater than $\mu_{d}$, it means that the driving route allows for more direct routes. Therefore, the city with a higher $\mu_{d}$ has more walkable routes as its trips on the driving routes correspond to a longer distance than its trips on the walking routes.

\section{Results}

\subsection{Street Patterns}

Figure 4 depicts a comparison of the SNs from the city centre of four selected capitals that represent metropolises, midsized cities, and small cities. The four capitals have different patterns of SNs, which vary significantly from one city to another and between the centre, business centres, and residential areas. Phnom Penh has orthogonal street grids with fewer cul-de-sacs in the centre while Naypyidaw and Ho Chi Minh City have "loops and lollipops" street patterns. Such street patterns are commonly disconnected from other routes. The SNs are very dense in Bangkok with zigzag patterns (warped parallel) and more cul-de-sacs.

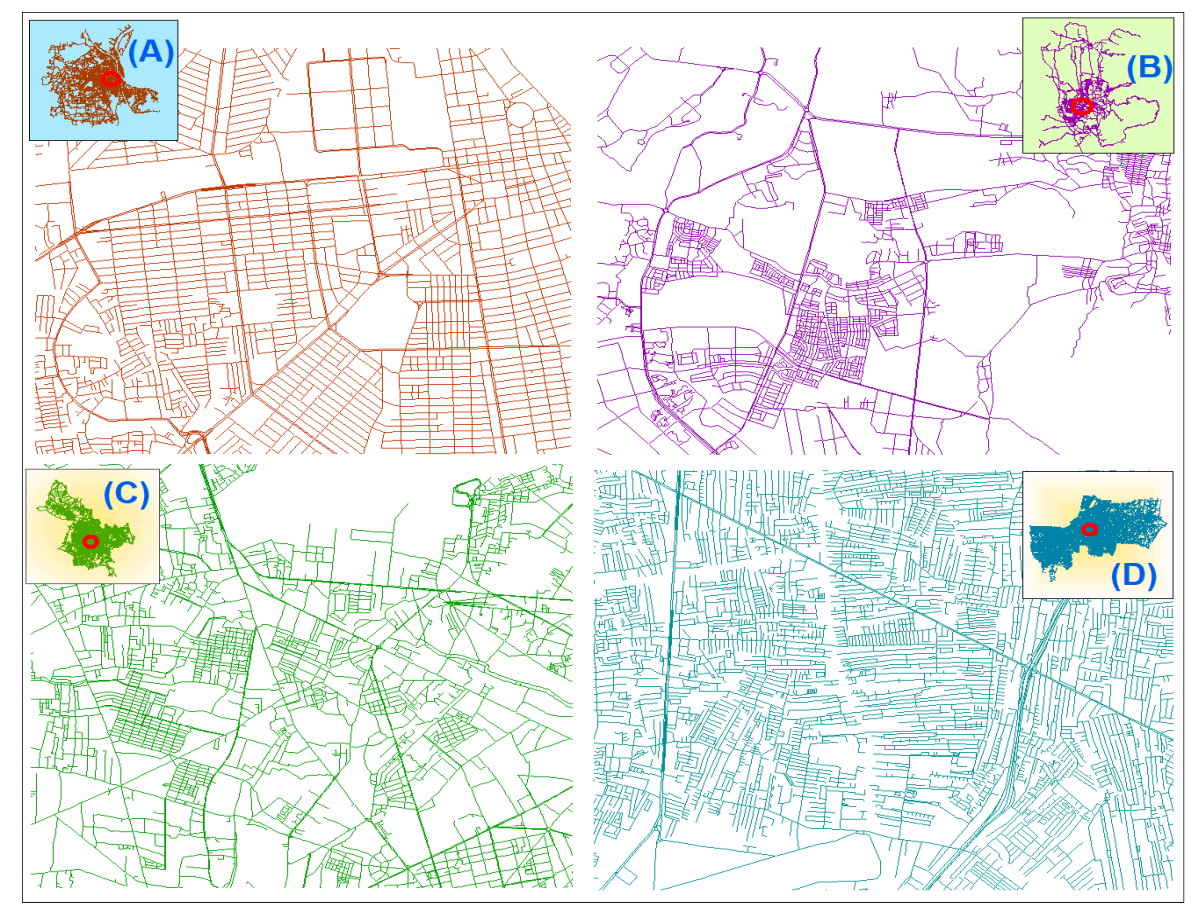

Figure 4. Comparisons of SN patterns in the city centre for four capitals in ASEAN-Phnom Penh (A), Naypyidaw (B), Ho Chi Minh City (C), and (D) Bangkok. 


\subsection{Street Distances}

The analysis of the average circuities indicates that an average circuity of the driving route exceeds an average circuity of the walking route in 22 (85\%) out of the 26 cities (Table 3). Only Mandalay, Jakarta, and Makassar have the average circuities of the walking routes of $24.5 \%, 6.4 \%$ and $5.1 \%$, respectively, which exceed the average circuities of the driving routes. Thus, the DSNs allow for more direct routes than the WSNs in these cities.

Table 3. The average circuity of driving and walking networks in ASCN.

\begin{tabular}{|c|c|c|c|c|c|c|c|c|}
\hline Cities & $\mu_{d}$ & $\mu_{w}$ & $\delta_{\mathrm{d}}(\mathrm{m})$ & $\delta_{w}(\mathrm{~m})$ & $\sum_{\mathrm{d}}(\mathbf{k m})$ & $\sum_{w}(\mathbf{k m})$ & d & $\varphi$ \\
\hline Bandar Seri Begawan & 1.64 & 1.41 & 84.2 & 57.9 & 4.9 & 78.5 & 1.91 & $56.1 \%$ \\
\hline Banyu Wangi & 1.30 & 1.29 & 77.4 & 76.7 & 98.2 & 100.4 & 0.08 & $3.4 \%$ \\
\hline Bangkok & 1.38 & 1.33 & 78.1 & 58.7 & 120.9 & 197.5 & 0.41 & $15.0 \%$ \\
\hline Battambang & 1.46 & 1.42 & 122.8 & 107.5 & 91.5 & 100.1 & 0.30 & $8.6 \%$ \\
\hline Cebu & 1.32 & 1.25 & 86.2 & 63.2 & 136.1 & 181.3 & 0.54 & $26.1 \%$ \\
\hline Chonburi & 3.21 & 2.14 & 212.7 & 148.5 & 28.7 & 56.9 & 8.88 & $93.9 \%$ \\
\hline Da Nang & 1.35 & 1.31 & 92.7 & 82.3 & 112.1 & 137.6 & 0.37 & $14.4 \%$ \\
\hline Davao & 1.45 & 1.41 & 92.4 & 84.1 & 73.4 & 83.8 & 0.33 & $9.7 \%$ \\
\hline Hanoi & 1.41 & 1.28 & 95.4 & 54.6 & 115.0 & 182.1 & 1.07 & $45.9 \%$ \\
\hline Ho Chi Minh City & 1.49 & 1.30 & 97.0 & 60.4 & 107.3 & 168.6 & 1.60 & $64.4 \%$ \\
\hline Jakarta & 1.40 & 1.43 & 86.8 & 83.8 & 126.2 & 139.6 & -0.23 & $-6.4 \%$ \\
\hline Johor Bahru & 1.39 & 1.30 & 83.9 & 64.6 & 135.0 & 177.2 & 0.78 & $31.2 \%$ \\
\hline Kota Kinabalu & 1.61 & 1.45 & 83.5 & 66.8 & 88.7 & 124.5 & 1.36 & $36.4 \%$ \\
\hline Kuala Lumpur & 1.91 & 1.50 & 122.8 & 74.5 & 120.6 & 206.3 & 3.41 & $82.1 \%$ \\
\hline Kuching & 1.29 & 1.28 & 63.9 & 50.6 & 83.5 & 139.0 & 0.11 & $4.8 \%$ \\
\hline Luang Prabang & 1.81 & 1.38 & 142.3 & 78.9 & 43.8 & 74.7 & 3.57 & $113.2 \%$ \\
\hline Makassar & 1.24 & 1.25 & 76.3 & 75.2 & 124.3 & 137.8 & -0.11 & $-5.1 \%$ \\
\hline Mandalay & 1.26 & 1.35 & 99.4 & 102.6 & 126.6 & 145.3 & -0.71 & $-24.5 \%$ \\
\hline Manila City & 1.32 & 1.26 & 92.2 & 72.7 & 146.1 & 180.5 & 0.52 & $24.2 \%$ \\
\hline Naypyidaw & 2.43 & 2.29 & 197.3 & 86.3 & 32.2 & 41.0 & 1.16 & $10.9 \%$ \\
\hline Phnom Penh & 1.38 & 1.32 & 104.5 & 69.9 & 113.7 & 171.9 & 0.53 & $19.9 \%$ \\
\hline Phuket & 1.54 & 1.46 & 99.8 & 88.9 & 85.8 & 104.2 & 0.69 & $18.0 \%$ \\
\hline Siem Reap & 1.48 & 1.40 & 117.0 & 91.1 & 95.6 & 113.1 & 0.69 & $20.7 \%$ \\
\hline Singapore & 1.61 & 1.30 & 107.2 & 50.4 & 110.1 & 252.8 & 2.66 & $103.3 \%$ \\
\hline Vientiane & 1.33 & 1.32 & 100.0 & 87.6 & 89.1 & 108.6 & 0.08 & $2.9 \%$ \\
\hline Yangon & 1.26 & 1.26 & 85.2 & 84.0 & 161.2 & 164.6 & 0.02 & $1.0 \%$ \\
\hline
\end{tabular}

Note: $\mu_{w}, \mu_{d}$ are the average circuity of DSNs and WSNs. $\delta_{\mathrm{d}}, \delta_{\mathrm{w}}=$ mean distance $(\mathrm{m})$ of routes along DSNs and WSNs. $\sum_{\mathrm{d}}$ and $\sum_{\mathrm{w}}$ are the total street length $(\mathrm{km})$ of the DSNs and WSNs. Cohen's $d_{d / w}$ is the effect size of the difference between $\mu_{\mathrm{w}}$ and $\mu_{\mathrm{d}}$, respectively. The $\varphi$ represents how much (\%) $\mu_{\mathrm{d}}$ exceeds $\mu_{\mathrm{w}}$.

A comparison of the mean distance of routes between DSNs $(\delta \mathrm{d})$ and WSNs $(\delta \mathrm{w})$ predicts how much distance can be saved between driving and walking trips by taking a directed route. Taking Singapore as an example, the average WSN was $50.4 \mathrm{~m}$, and the average DSN was $107.2 \mathrm{~m}$. Thus, the walking trip is $56.8 \mathrm{~m}$ shorter than the driving trip. The different mean distances are associated with street sizes and larger spatial extents of the city that require higher trip distance. In addition, cities with more orthogonal street grids, such as Makassar (25\%), Cebu (25\%), and Yangon (26\%), tend to have the least average circuity. Conversely, cities with curvilinear SNs, such as in Chonburi, Naypyidaw, and Luang Prabang, have the most circuitous average for both DSNs and WSNs.

The $\varphi$ ratios and Cohen's d show different percentages of DSNs versus WSNs (Table 3). Singapore and Luang Prabang exhibit the highest values of $\varphi$. In each of these cities, the average DSN is over $100 \%$ more circuitous than the average WSN. In contrast, in Mandalay and Jakarta City, the average DSN is $24.5 \%$ and $6.4 \%$ less circuitous than the average WSN, respectively.

Within the $1500 \mathrm{~m}$ buffer of each study area, the total lengths of DSNs in Yangon (161.2 km), Manila City $(146.1 \mathrm{~km})$, and Cebu $(136.1 \mathrm{~km})$ correspond to the 1st, 2nd, and 3rd longest, respectively, while Singapore (252.8 m) and Kuala Lumpur (206.3m) have the longest WSNs, respectively. 


\subsection{Street Density}

The different features of the DSNs and WSNs are presented in Table 4 and Figure 4 . The node densities of the DSNs in Makassar and Kuching are the highest at 189.4 intersections $/ \mathrm{km}^{2}$ and 185.7 intersections $/ \mathrm{km}^{2}$, respectively. In contrast, node densities in Chonburi and Naypyidaw are the lowest at just 14.90 intersections $/ \mathrm{km}^{2}$ and 17.1 intersections $/ \mathrm{km}^{2}$, respectively. The node density for WSNs is the highest in Singapore with 442.6 intersections $/ \mathrm{km}^{2}$, while Naypyidaw and Chonburi are the lowest with 23.5 intersections $/ \mathrm{km}^{2}$ and 44.0 intersections $/ \mathrm{km}^{2}$, respectively. Regarding the street densities per km², Makassar (20.2), Yangon (19.6), and Manila City (18.7) have higher street densities per $\mathrm{km}^{2}$ than other cities for DSNs, whereas Singapore (32.4), Bangkok (24.1), and Kuala Lumpur (23.3) rank the 1st, 2nd, and 3rd for the highest street densities per $\mathrm{km}^{2}$, respectively.

Topological measures were used to explain the complexity, connectedness, and resilience of the city. On average, the cities with a high average street per node indicate a great connectedness of streets. For example, Singapore has the highest intersection density of 382.4 for the WSNs, whereas Makassar has the highest intersection density of 160.8 for the DSNs. The highest average streets per node with 3.34 and 3.23 of the DSNs were in Phnom Penh and Yangon, respectively. The cities with the highest betweenness centrality show that their streets are sparse and disconnected due to a high density of street dead-ends and improper street design. Chonburi and Naypyidaw are the cities with the highest betweenness centralities of $9 \%$ and $8 \%$ for DSNs and $7 \%$ and $6 \%$ for WSNs, respectively (Table 4 ).

A comparison of edge density for metropolises $(\mathrm{A} 1,2)$, midsized cities $(\mathrm{B} 1,2)$, and small cities $(\mathrm{C} 1,2)$ is shown in Figure 5. Jakarta is a metropolis whose edge densities of both DSNs and WSNs are highly dispersed, except the very northeast of the capital where edge densities are very loose. The edge densities for Kuala Lumpur are similarly dispersed in the whole city, but the highest densities are in the northeast parts. Unlike Jakarta and Kuala Lumpur, Vientiane has very high edge densities in the central-southern area, whereas the rest of the city, especially in the northern areas, has very low density. This result indicates that Vientiane is a monopolar city that retains a single centre, as even after the expansion of the city. In addition, the edge densities of WSNs in most cities are commonly higher than those of DSNs (e.g., DSNs and WSNs in Singapore in Figure 6). Moreover, the edge densities of both DSNs and WSNs are denser in the metropolis than in the midsize and small cities. 


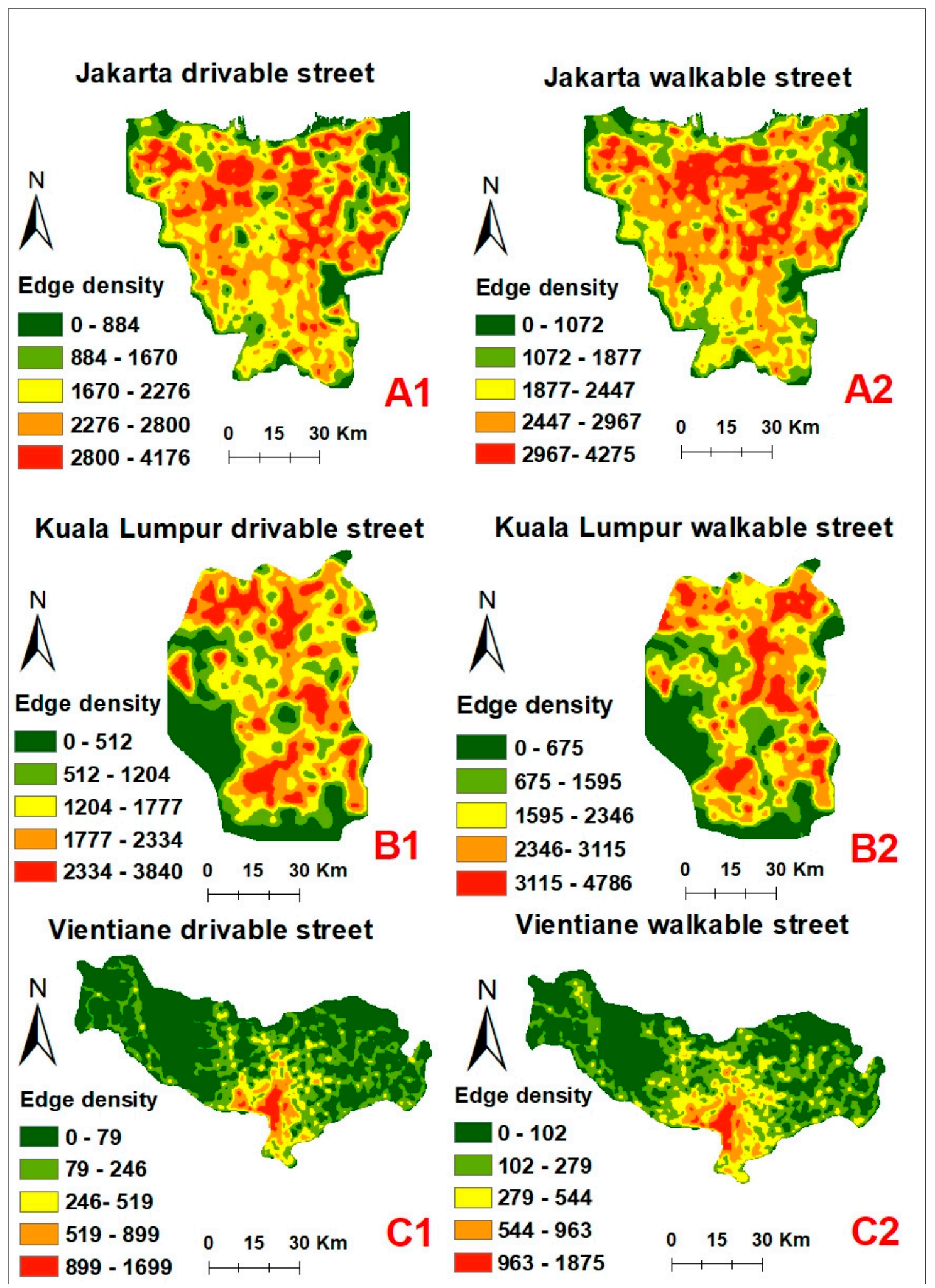

Figure 5. The spatial distribution of the edge density of driving and walking SNs of the metropolis $(\mathbf{A 1}, \mathbf{A} 2)$, midsized city $(\mathbf{B 1}, \mathbf{B} 2)$, and small city $(\mathbf{C 1}, \mathbf{C} 2)$ using the kernel density estimation (KDE) in a default searching radius. The red colour represents the highest edge density for each SN type. 


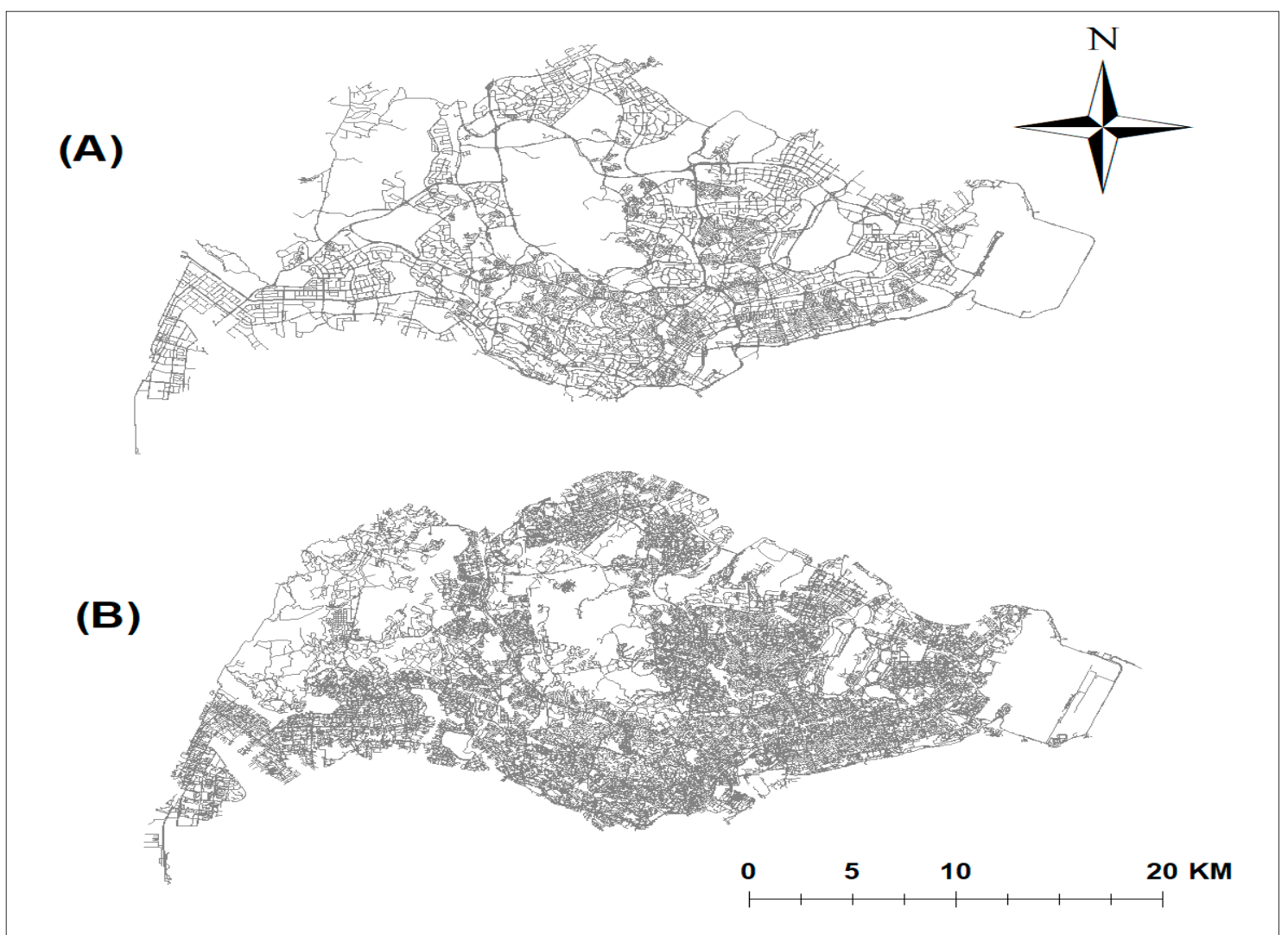

Figure 6. Comparison of drivable (A) and walkable street networks (B) in Singapore.

\section{Discussion and Conclusions}

\subsection{Comparison of DSNs and WSNs across the ASCN}

The different average circuities of the DSNs and WSNs provide information about which cities allow for more directed driving or walking trips to reach destinations at the shortest distance. The results of the study show that across the small cities of the ASCN, Kuching and Banyu Wangi have the least average circuities and mean distances of the WSNs, which indicates that streets in these cities allow for more directed routes of walking than of driving compared with the other small cities (Table 3). Similarly, if we look across the midsized cities, Cebu and Manila City have the least average circuities and lowest mean distances for the WSNs compared with those of the DSNs, which means that these midsized cities have more straight-line route accessibility for walking than other midsized cities. Moreover, the average circuity of the DSNs in Singapore is more circuitous than the WSNs. Thus, streets in Singapore tend to allow for walking rather than driving trips. Furthermore, the street density, average streets per node, and average street segment length show the better street infrastructure (e.g., connected streets) that each city has provided for the people. Kota Kinabalu has the highest street density with high average streets per node for the DSNs compared with other small cities, but Kuching has the highest street density with high average streets per node for the WSNs. Moreover, Kuching is better than other small cities in terms of WSN provision. By examining these indicators for the midsized and metropolis cities, Macassar is a leading city with the highest street density for the DSNs, but the street density of walking in Phnom Penh is much denser than other cities. Hence, Macassar has good connected streets for driving, while Phnom Penh has good connected streets for walking in the city centre. Among the metropolises, Singapore remains a leading city for its walking street density. 
Table 4. The measures of two types of SNs in 26 pilot cities.

\begin{tabular}{|c|c|c|c|c|c|c|c|c|c|c|c|c|c|c|c|c|c|c|}
\hline \multirow{2}{*}{ City $\quad$ Measure } & \multicolumn{9}{|c|}{ DSNs } & \multicolumn{9}{|c|}{ WSNs } \\
\hline & $\mathbf{n}$ & $\kappa$ & $\eta$ & $\rho$ & $\gamma_{(\mathrm{km})}$ & $\varepsilon_{(\mathrm{km})}$ & $\lambda_{(\mathrm{km})}$ & $\alpha$ & $\beta$ & $\mathbf{n}$ & $\kappa$ & $\eta$ & $\rho$ & $\gamma_{(\mathrm{km})}$ & $\varepsilon_{(\mathrm{km})}$ & $\lambda_{(\mathrm{km})}$ & $\alpha$ & $\beta$ \\
\hline Bandar Seri Begawan & 337 & 297 & 59.7 & 52.6 & 10.0 & 7.2 & 84.2 & 2.95 & 0.05 & 944 & 798 & 167.1 & 141.3 & 27.2 & 13.9 & 57.9 & 2.89 & 0.02 \\
\hline Banyu Wangi & 956 & 763 & 126.5 & 100.9 & 25.1 & 13.0 & 77.4 & 2.70 & 0.02 & 985 & 788 & 130.3 & 104.2 & 26.5 & 13.3 & 76.7 & 2.71 & 0.02 \\
\hline Bangkok & 1165 & 915 & 142.3 & 111.7 & 23.7 & 14.8 & 78.1 & 2.72 & 0.02 & 2518 & 1989 & 307.5 & 242.9 & 47.9 & 24.1 & 58.7 & 2.70 & 0.01 \\
\hline Battambang & 515 & 448 & 63.4 & 55.2 & 21.8 & 11.3 & 122.8 & 2.99 & 0.03 & 642 & 561 & 79.1 & 69.1 & 24.7 & 12.3 & 107.5 & 2.97 & 0.02 \\
\hline Cebu & 1189 & 909 & 135.5 & 103.6 & 5.8 & 15.5 & 86.2 & 2.73 & 0.02 & 2265 & 1646 & 258.1 & 187.6 & 41.2 & 20.7 & 63.2 & 2.58 & 0.01 \\
\hline Chonburi & 112 & 84 & 14.9 & 11.2 & 7.4 & 3.8 & 212.7 & 2.59 & 0.09 & 330 & 220 & 44.0 & 29.3 & 14.8 & 7.6 & 148.5 & 2.38 & 0.06 \\
\hline Da Nang & 873 & 724 & 116.7 & 96.8 & 26.5 & 15.0 & 92.7 & 2.83 & 0.02 & 1237 & 992 & 165.3 & 132.6 & 36.7 & 18.4 & 82.3 & 2.76 & 0.02 \\
\hline Davao & 565 & 503 & 96.3 & 85.8 & 24.3 & 12.5 & 92.4 & 2.92 & 0.03 & 702 & 624 & 119.7 & 106.4 & 28.5 & 14.3 & 84.1 & 2.92 & 0.03 \\
\hline Hanoi & 862 & 71 & 97.6 & 81.3 & 22.0 & 13.0 & 95.4 & 2.90 & 0.02 & 2537 & 1857 & 286.5 & 209.7 & 40.8 & 20.6 & 54.6 & 2.67 & 0.01 \\
\hline Ho Chi Minh City & 740 & 667 & 93.4 & 84.2 & 18.1 & 13.5 & 97.0 & 3.11 & 0.02 & 2078 & 1630 & 262.2 & 205.7 & 42.4 & 21.3 & 60.4 & 2.75 & 0.01 \\
\hline Jakarta & 980 & 917 & 121.6 & 113.7 & 27.2 & 15.7 & 86.8 & 3.01 & 0.02 & 1120 & 1040 & 138.9 & 129.0 & 34.4 & 17.3 & 83.8 & 3.01 & 0.02 \\
\hline Johor Bahru & 1202 & 1013 & 145.4 & 122.5 & 30.0 & 16.3 & 83.9 & 2.76 & 0.02 & 2071 & 1673 & 250.5 & 202.3 & 42.6 & 21.4 & 64.6 & 2.71 & 0.01 \\
\hline Kota Kinabalu & 773 & 661 & 136.3 & 116.6 & 21.5 & 15.6 & 83.5 & 2.80 & 0.03 & 1402 & 1125 & 247.3 & 198.4 & 43.3 & 22.0 & 66.8 & 2.68 & 0.01 \\
\hline Kuala Lumpur & 695 & 641 & 78.5 & 72.4 & 17.7 & 13.6 & 122.8 & 2.93 & 0.02 & 2072 & 1677 & 233.9 & 189.3 & 46.2 & 23.3 & 74.5 & 2.71 & 0.01 \\
\hline Kuching & 1074 & 764 & 185.7 & 132.1 & 22.2 & 14.4 & 63.9 & 2.48 & 0.03 & 2124 & 1628 & 367.2 & 281.5 & 47.1 & 24.0 & 50.6 & 2.61 & 0.01 \\
\hline Luang Prabang & 225 & 191 & 42.0 & 35.6 & 15.1 & 8.2 & 142.3 & 2.83 & 0.06 & 739 & 544 & 137.8 & 101.4 & 27.6 & 13.9 & 78.9 & 2.59 & 0.02 \\
\hline Makassar & 1165 & 989 & 189.4 & 160.8 & 35.7 & 20.2 & 76.3 & 2.85 & 0.02 & 1331 & 1109 & 216.4 & 180.3 & 44.7 & 22.4 & 75.2 & 2.81 & 0.01 \\
\hline Mandalay & 839 & 765 & 96.7 & 88.2 & 27.4 & 14.6 & 99.4 & 3.14 & 0.02 & 958 & 844 & 110.4 & 97.3 & 33.4 & 16.7 & 102.6 & 3.05 & 0.02 \\
\hline Manila City & 1012 & 944 & 130.7 & 120.8 & 29.1 & 18.7 & 92.2 & 3.21 & 0.02 & 1671 & 1459 & 213.8 & 186.7 & 45.8 & 23.1 & 72.7 & 3.04 & 0.01 \\
\hline Naypyidaw & 114 & 106 & 17.1 & 15.9 & 7.8 & 4.8 & 197.3 & 3.12 & 0.08 & 157 & 143 & 23.5 & 21.4 & 12.1 & 6.1 & 86.3 & 3.07 & 0.07 \\
\hline Phnom Penh & 676 & 648 & 90.4 & 86.7 & 26.7 & 15.2 & 104.5 & 3.34 & 0.02 & 1672 & 1459 & 223.6 & 195.1 & 45.7 & 23.0 & 69.9 & 3.04 & 0.01 \\
\hline Phutket & 659 & 510 & 78.5 & 60.8 & 18.8 & 10.2 & 99.8 & 2.66 & 0.03 & 899 & 686 & 107.1 & 81.7 & 24.5 & 12.4 & 88.9 & 2.66 & 0.02 \\
\hline Siem Reap & 616 & 498 & 70.6 & 57.1 & 20.9 & 11.0 & 117.0 & 2.77 & 0.03 & 912 & 744 & 104.2 & 85.3 & 25.9 & 13.0 & 91.1 & 2.81 & 0.02 \\
\hline Singapore & 677 & 644 & 86.7 & 82.4 & 15.9 & 14.1 & 107.2 & 3.14 & 0.03 & 3457 & 2987 & 442.6 & 382.4 & 64.3 & 32.4 & 50.4 & 2.54 & 0.01 \\
\hline Vientiane & 653 & 540 & 92.6 & 76.6 & 22.7 & 12.6 & 100.0 & 2.81 & 0.02 & 924 & 744 & 131.1 & 105.5 & 30.7 & 15.4 & 87.6 & 2.75 & 0.02 \\
\hline Yangon & 1205 & 1173 & 146.5 & 142.6 & 38.5 & 19.6 & 85.2 & 3.23 & 0.02 & 1252 & 1216 & 152.2 & 147.8 & 40.0 & 20.0 & 84.0 & 3.22 & 0.02 \\
\hline
\end{tabular}

Note: Number of nodes $(\mathrm{n})$, intersection counts $(\kappa)$, node density $(\eta)$, intersection density $(\rho)$, edge density $(\gamma)$, street density $(\varepsilon)$, average street segment length $(\lambda)$, average streets per node $(\alpha)$, and betweenness centrality $(\beta)$. 
In general, the patterns of streets and connectivity substantially vary from the city centre, business districts, residential areas, and suburban areas. Moreover, the high street density and intersection density of the cities promote better flow of traffic and accessibility due to the street orthogonality and connectivity. Our study found that some cities (e.g., Macassar, Phnom Penh, and Yangon) have orthogonal street patterns in the centre which are more connected than other cities in the ASCN. In addition, the cities with high densities of nodes, edges, streets, and intersections are more accessible to reach destinations. High accessibility will boost urban socio-economic activities [47]. He et al. [40] emphasize that commercial activities prefer streets with high connectivity, while specialty shops like streets with high closeness centrality, and supermarkets prefer a location with high betweenness centrality of streets. There are different factors affecting street designs and their performance. Population density, GDP growth rate, building density, and total street length per inhabitant are the three important factors [27]. Conversely, the different patterns of SNs affect traffic flow, traveller's behaviour, and safety [48]. For example, Loo et al. [49] revealed that SNs play a vital role in people's mobility decisions as to whether to use a private vehicle or public transport mode. In line with Loo's study, Ha et al. [50] indicate that Cambodian people decide to own private vehicles because of disconnected streets, long distances to reach destinations, and unreliable public transport services.

\subsection{Implications of $S N$ s for the ASCN}

Using smart technologies and innovations in urban development is a powerful approach to solve the ASCN's urban challenges. Smart technologies can transform the cities for a better quality of life and sustainable growth. However, many of the challenges for ASCN cities to become smart cities likely exceed the scope and capabilities of the current knowledge and skills of ASCN leaders and the people, which may make it difficult to achieve promising goals in a timely way [3]. The shortage of capacities and experience of the implementers for the majority of these cities tends to constitute the major barriers for the effective transformation of each pilot city into a smart city. Specifically, for the transport system, a lack of transport infrastructure for alternative modes of travel (e.g., walking and cycling accessibility) in most of the cities is one of the challenges leading to an increase in private vehicle ownership in the region. For example, in 2015, Ho Chi Minh City reached 900 vehicles per 1000 people, whereas Bangkok had 1000 vehicles per 1000 inhabitants in 2016. The number of vehicles in Malaysia has surpassed Bangkok and Ho Chi Minh City, reaching 1300 private vehicles per 1000 Malaysian people since 2014 [36]. As such, traffic congestion has become a critical issue in these cities [51]. Applying smart technologies in the transport system can help cities to tackle traffic issues and achieve optimized usage of public resources, such as transportation infrastructure, energy, and natural resources [52]. However, smart transportation is applicable whenever the road infrastructure is appropriately designed or properly retrofitted for installing smart technology infrastructure. Our study shows that transport systems in some cities fail to meet this prerequisite due to the interspersed street patterns that are disconnected and automobile-oriented. Such cities need huge investments and efforts to transform the old streets into a safe and sustainable public space. In such initiatives, designers of newly constructed streets should pay attention to multimodal street design that offers alternative modes of travel, including differentiation of street lanes for pedestrians, motorbikes, and cars; street lighting and signals; street trees, and safety. The multimodal street design has the potential to improve traffic congestion, reduce energy consumption, promote local business, and sustain the environment. Importantly, to plan and design such streets, an analysis of the current street patterns is of particular relevance. An analysis of SNs can produce valuable information about street patterns, travellers' behaviours [53], location preference for households and firms [40], urban characteristics [38], and traffic flow and safety. This information is a useful guide for the decision-making process to improve and design road systems that work for a sustainable transport system and is suitable for smart technology applications. Our research findings highlight the important characteristics of the SNs of the 26 pilot cities. With detailed street characteristics, planners and policymakers can choose the right 
locations within the cities to retrofit SNs or to design SNs that serve multiple purposes and fit smart technology applications.

\subsection{Contribution to the Literature on Transport in the ASCN}

This study contributes significantly to the body of knowledge from previous studies on urban forms and street analysis in the region. In particular, the present study can deepen our understanding of the differences between DSNs and WSNs in the ASCN. The previous studies dedicated to this region focus on an individual city or a location rather than on multi-scale and multiple locations, and large sample sizes of the SNs. For example, Patarasuk [8] analysed the road network connectivity and land-cover dynamics in Lop Buri province, Thailand [8]. Soesanti and Nakai [54] examined the SNs in Bandung City, Indonesia, whereas Sanders et al. [55] assessed the liveable streets in Hanoi, Vietnam and Henderson [32] measured Singaporean walkable streets for tourists [56]. Other studies have concentrated on energy, traffic accidents [18], urban forms [57], flooding [23], and paratransit [33]. This study instead provides aggregate information about the DSNs and WSNs and urban forms of the principal representative cities in the region.

\subsection{Conclusions}

This study has provided an in-depth analysis of drivable street networks (DSNs) and walkable street networks (WSNs) in the 26 pilot cities of the ASEAN smart cities network (ASCN), where such studies have been rare. The patterns of streets substantially vary from one city to another, and from the city centre, business districts, residential areas, and suburban areas. Large cities have denser SNs than the mature and small cities and thus become greater potential hubs to connect to other core network corridors and are more accessible to the basic services. The cities with orthogonal street grids, high street density, intersection density, and fewer cul-de-sacs have good accessibility to reach destinations. In contrast, some other cities have more curvilinear and circuitous street networks (SNs) with many missing links to other streets, which in turn are prone to disruption.

To achieve the promising goals of the ASNC for a sustainable transport system, it is crucial to understand the challenges of the transport system in each city. SN metrics are essential for measuring street features, travel demand, and development. The analysis of WSNs and DSNs could reflect policies on the alternative modes of travel. Future designs of street layouts should incorporate facilities, services, and safety design features to promote walking and biking rather than a vehicle-dominant orientation. This will eventually lead to increased health and wellness among urban dwellers and improve active urban mobility. Each city should have a comprehensive transport development plan as it could reduce the expansion of unstructured street patterns that are affected by illegal constructions or settlement of local people in the suburban areas.

Future research could combine land use, population density, economic growth, and points of interest to assess the distance and accessibility to fundamental services, such as jobs, markets, healthcare, and other governmental services. Such studies would offer more insight into the SNs and urban forms in this region.

Author Contributions: All four authors contributed equally to this paper. Yat Yen collected and wrote the manuscript. Pengjun Zhao designed the research work and provided advice and funding. Muhammad Tayyab Sohail reviewed the literature and structured the manuscript, and Earl Bailey analysed the data and edited the English and style of the manuscript.

Funding: This research received no external funding.

Acknowledgments: This research was supported by the Boya Post-doctoral Research Program, Peking University and by a Senior Fellowship grant from the Center for Khmer Studies, Cambodia. The authors would like to thank Leo Atwood for his kind editing and proofreading of our English language. The authors also express sincere gratitude to the Journal Editor, Helen Hong, and the anonymous reviewers who spent their valued time to provide constructive comments and assistance to improve the quality of this paper.

Conflicts of Interest: The authors confirm no potential conflict of interest to declare. 


\section{References}

1. Ahmed, K.; Bhattacharya, M.; Shaikh, Z.; Ramzan, M.; Ozturk, I. Emission intensive growth and trade in the era of the Association of Southeast Asian Nations (ASEAN) integration: An empirical investigation from ASEAN-8. J. Clean. Prod. 2017, 154, 530-540. [CrossRef]

2. Chen, F.; Wang, J.; Wu, J.; Chen, X.; Zegras, P.C. Monitoring road safety development at regional level: A case study in the ASEAN region. Accid. Anal. Prev. 2017, 106, 437-449. [CrossRef] [PubMed]

3. Ludher, E.; Sharda, N.; Lal, R.; Chow, C.; Ng, J. Smart Cities in South East Asia; McKinsey Global Institute: Singapore, 2018 ; p. 80.

4. Jonathan, W.; Diaan-Yi, L.; Mukund, S.; Yap, S.-E. Smart Cities in South East Asia; McKinsey Global Institute (MGI): Singapore, 2018.

5. Haque, M.M.; Chin, H.C.; Debnath, A.K. Sustainable, safe, smart—three key elements of Singapore's evolving transport policies. Transp. Policy 2013, 27, 20-31. [CrossRef]

6. Cao, X.; Feiwen, L.; Huiling, C.; Liu, Y. Circuity Characteristics of Urban Travel Based on GPS Data: A Case Study of Guangzhou. Sustainability 2017, 9, 2156. [CrossRef]

7. Sharifi, A. Resilient urban forms: A review of literature on streets and street networks. Build. Environ. 2019, 147, 171-187. [CrossRef]

8. Patarasuk, R. Road network connectivity and land-cover dynamics in Lop Buri province, Thailand. J. Transp. Geogr. 2013, 28, 111-123. [CrossRef]

9. Giacomin, D.J.; Levinson, D.M. Road network circuity in metropolitan areas. Environ. Plan. B Plan. Des. 2015, 42, 1040-1053. [CrossRef]

10. Godwin, A.; Price, A.M. Bicycling and walking in the Southeast USA: Why is it rare and risky? J. Transp. Health 2016, 3, 26-37. [CrossRef]

11. Huang, J.; Levinson, D.M. Circuity in urban transit networks. J. Transp. Geogr. 2015, 48, 145-153. [CrossRef]

12. Caset, F.; Vale, D.S.; Viana, C.M. Measuring the Accessibility of Railway Stations in the Brussels Regional Express Network: A Node-Place Modeling Approach. Netw. Spat. Econ. 2018, 18, 495-530. [CrossRef]

13. Boeing, G. The Morphology and Circuity of Walkable and Drivable Street Networks. SocArXiv 2018, 271-287. [CrossRef]

14. Yen, Y.; Wang, Z.; Shi, Y.; Xu, F.; Soeung, B.; Sohail, M.T.; Rubakula, G.; Juma, S.A. The predictors of the behavioral intention to the use of urban green spaces: The perspectives of young residents in Phnom Penh, Cambodia. Habitat Int. 2017, 64, 98-108. [CrossRef]

15. Ratanavaraha, V.; Jomnonkwao, S. Trends in Thailand $\mathrm{CO}_{2}$ emissions in the transportation sector and Policy Mitigation. Transp. Policy 2015, 41, 136-146. [CrossRef]

16. Tarigan, A.K.M.; Sagala, S.; Samsura, D.A.A.; Fiisabiilillah, D.F.; Simarmata, H.A.; Nababan, M. Bandung City, Indonesia. Cities 2016, 50, 100-110. [CrossRef]

17. Emberger, G. Urban Transport in Ho Chi Minh City, Vietnam. In Sustainable Ho Chi Minh City: Climate Policies for Emerging Mega Cities; Katzschner, A., Waibel, M., Schwede, D., Katzschner, L., Schmidt, M., Storch, H., Eds.; Springer International Publishing: Cham, Switzerland, 2016; pp. 175-191. [CrossRef]

18. Kitamura, Y.; Hayashi, M.; Yagi, E. Traffic problems in Southeast Asia featuring the case of Cambodia's traffic accidents involving motorcycles. IATSS Res. 2018, 42, 163-170. [CrossRef]

19. Karduni, A.; Kermanshah, A.; Derrible, S. A protocol to convert spatial polyline data to network formats and applications to world urban road networks. Sci. Data 2016, 3, 160046. [CrossRef]

20. Marshall, S.; Gil, J.; Kropf, K.; Tomko, M.; Figueiredo, L. Street Network Studies: From Networks to Models and their Representations. Netw. Spat. Econ. 2018, 18, 735-749. [CrossRef]

21. Schneider, A.; Mertes, C.M.; Tatem, A.J.; Tan, B.; Sulla-Menashe, D.; Graves, S.J.; Patel, N.N.; Horton, J.A.; Gaughan, A.E.; Rollo, J.T.; et al. A new urban landscape in East-Southeast Asia, 2000-2010. Environ. Res. Lett. 2015, 10, 034002. [CrossRef]

22. Lee, B.-H.; Jung, W.-S. Analysis on the urban street network of Korea: Connections between topology and meta-information. Phys. A Stat. Mech. Appl. 2018, 497, 15-25. [CrossRef]

23. Wongsa, S.; Vichiensan, V.; Piamsa-nga, N.; Nakamura, S. Urban Flooding and Adaptation to Climate Change in Sukhumvit Area, Bangkok, Thailand. In Proceedings of the New Trends in Urban Drainage Modelling, UDM 2018, Green Energy and Technology, Palermo, Italy, 23-26 September 2018; Springer: Cham, Switzerland, 2019; pp. 644-648. 
24. Gilbuena, R., Jr.; Kawamura, A.; Medina, R.; Amaguchi, H.; Nakagawa, N.; Bui, D.D. Environmental impact assessment of structural flood mitigation measures by a rapid impact assessment matrix (RIAM) technique: A case study in Metro Manila, Philippines. Sci. Total Environ. 2013, 456, 137-147. [CrossRef]

25. Duy, P.N.; Chapman, L.; Tight, M. Resilient transport systems to reduce urban vulnerability to floods in emerging-coastal cities: A case study of Ho Chi Minh City, Vietnam. Travel Behav. Soc. 2019, 15, $28-43$. [CrossRef]

26. Thanvisitthpon, N. Impact of land use transformation and anti-flood infrastructure on flooding in world heritage site and peri-urban area: A case study of Thailand's Ayutthaya province. J. Environ. Manag. 2019, 247, 518-524. [CrossRef] [PubMed]

27. Dingil, A.E.; Schweizer, J.; Rupi, F.; Stasiskiene, Z. Transport indicator analysis and comparison of 151 urban areas, based on open source data. Eur. Transp. Res. Rev. 2018, 10, 58. [CrossRef]

28. Hu, F.; Zhang, X.; Hu, M.; Cook, D.L. Chinese Enterprises' Investment in Infrastructure Construction in Cambodia. Asian Perspect. 2019, 43, 177-207. [CrossRef]

29. World Bank. The Urban Development in Phnom Penh. World Bank 2017, 14-72.

30. Fesselmeyer, E.; Liu, H. How much do users value a network expansion? Evidence from the public transit system in Singapore. Reg. Sci. Urban Econ. 2018, 71, 46-61. [CrossRef]

31. Robinson, I.M. Mega Urban Regions of Southeast Asia; UBC Press: Vancouver, BC, Canada, 2011.

32. Wang, Y.; Chen, L.; Kubota, J. The relationship between urbanization, energy use and carbon emissions: Evidence from a panel of Association of Southeast Asian Nations (ASEAN) countries. J. Clean. Prod. 2016, 112, 1368-1374. [CrossRef]

33. Phun, V.K.; Kato, H.; Chalermpong, S. Paratransit as a connective mode for mass transit systems in Asian developing cities: Case of Bangkok in the era of ride-hailing services. Transp. Policy 2019. [CrossRef]

34. Wey, W.-M.; Huang, J.-Y. Urban sustainable transportation planning strategies for livable City's quality of life. Habitat Int. 2018, 82, 9-27. [CrossRef]

35. Hanna, R.; Kreindler, G.; Olken, B.A. Citywide effects of high-occupancy vehicle restrictions: Evidence from "three-in-one" in Jakarta. Science 2017, 357, 89-93. [CrossRef]

36. Nguyen, D.C.; Hoang, H.D.; Hoang, H.T.; Bui, Q.T.; Nguyen, L.P. Modal Preference in Ho Chi Minh City, Vietnam: An Experiment With New Modes of Transport. SAGE Open 2019, 9, 2-14. [CrossRef]

37. Pongprasert, P.; Kubota, H. Switching from motorcycle taxi to walking: A case study of transit station access in Bangkok, Thailand. IATSS Res. 2017, 41, 182-190. [CrossRef]

38. Boeing, G. OSMnx: New methods for acquiring, constructing, analyzing, and visualizing complex street networks. Comput. Environ. Urban Syst. 2017, 65, 126-139. [CrossRef]

39. Ibnoulouafi, A.; El Haziti, M. Density centrality: Identifying influential nodes based on area density formula. Chaos Solitons Fractals 2018, 114, 69-80. [CrossRef]

40. He, S.; Yu, S.; Shao, X.; Wei, P. A spatial design network analysis of street networks and the locations of leisure entertainment activities: A case study of Wuhan, China. Sustain. Cities Soc. 2018, 44, 880-887. [CrossRef]

41. Boeing, G. A multi-scale analysis of 27,000 urban street networks: Every US city, town, urbanized area, and Zillow neighborhood. Environ. Plan. B: Urban Anal. City Sci. 2018, 45, 1-19. [CrossRef]

42. Mülligann, C.; Janowicz, K.; Ye, M.; Lee, W.-C. Analyzing the spatial-semantic interaction of points of interest in volunteered geographic information. In Proceedings of the International Conference on Spatial Information Theory, COSIT 2011, Belfast, ME, USA, 12-16 September 2011; Lecture Notes in Computer Science. Springer: Berlin/Heidelberg, Germany; Volume 6899, pp. 350-370.

43. Zhang, L.; Pfoser, D. Using OpenStreetMap point-of-interest data to model urban change-A feasibility study. PLOS ONE 2019, 14, e0212606. [CrossRef]

44. Touya, G.; Antoniou, V.; Olteanu-Raimond, A.-M.; Van Damme, M.-D. Assessing Crowdsourced POI Quality: Combining Methods Based on Reference Data, History, and Spatial Relations. ISPRS Int. J. Geo-Inf. 2017, 6, 80. [CrossRef]

45. Ather, A. A Quality Analysis of Open Street Map Data. Master' Thesis, University College London, London, UK, 2009.

46. Basiri, A.; Jackson, M.; Amirian, P.; Pourabdollah, A.; Sester, M.; Winstanley, A.; Moore, T.; Zhang, L. Quality assessment of OpenStreetMap data using trajectory mining. Geo-Spat. Inf. Sci. 2016, 19, 56-68. [CrossRef]

47. Rui, Y.; Ban, Y. Exploring the relationship between street centrality and land use in Stockholm. Int. J. Geogr. Inf. Sci. 2014, 28, 1425-1438. [CrossRef] 
48. Zhang, Y.; Wang, X.; Zeng, P.; Chen, X. Centrality Characteristics of Road Network Patterns of Traffic Analysis Zones. Transp. Res. Rec. 2011, 2256, 16-24. [CrossRef]

49. Loo, L.Y.L.; Corcoran, J.; Mateo-Babiano, D.; Zahnow, R. Transport mode choice in South East Asia: Investigating the relationship between transport users' perception and travel behaviour in Johor Bahru, Malaysia. J. Transp. Geogr. 2015, 46, 99-111. [CrossRef]

50. Ha, T.V.; Asada, T.; Arimura, M. Determination of the influence factors on household vehicle ownership patterns in Phnom Penh using statistical and machine learning methods. J. Transp. Geogr. 2019, 78, 70-86. [CrossRef]

51. Sugiarto, S.; Miwa, T.; Morikawa, T. The tendency of public's attitudes to evaluate urban congestion charging policy in Asian megacity perspective: Case a study in Jakarta, Indonesia. Case Stud. Transp. Policy 2018. [CrossRef]

52. Ruhlandt, R.W.S. The governance of smart cities: A systematic literature review. Cities 2018, 81, 1-23. [CrossRef]

53. Shatu, F.; Yigitcanlar, T. Development and validity of a virtual street walkability audit tool for pedestrian route choice analysis-SWATCH. J. Transp. Geogr. 2018, 70, 148-160. [CrossRef]

54. Soesanti, S.; Nakai, N. Street Network in Bandung City, Indonesia: Comparison between City Center and New Commercial Area. Int. Sch. Sci. Res. Innov. 2012, 4, 1104-1114.

55. Sanders, P.; Zuidgeest, M.; Geurs, K. Liveable streets in Hanoi: A principal component analysis. Habitat Int. 2015, 49, 547-558. [CrossRef]

56. Henderson, J. Making cities more walkable for tourists: A view from Singapore's streets. Int. J. Tour. Cities 2018, 4, 285-297. [CrossRef]

57. Kim, Y. Mandalay, Myanmar: The remaking of a South-east Asian hub in a country at the crossroads. Cities 2018, 72, 274-286. [CrossRef]

(C) 2019 by the authors. Licensee MDPI, Basel, Switzerland. This article is an open access article distributed under the terms and conditions of the Creative Commons Attribution (CC BY) license (http://creativecommons.org/licenses/by/4.0/). 